\title{
Supplementation with L-Carnitine improves uterine receptivity in women with prior implantation failure during frozen embryos transfer: A double-blinded, randomized, placebo-controlled clinical trial
}

\author{
Yehia Edris, Ehab Barakat
}

Department of Obstetrics and Gynecology, Faculty of Medicine, Banha University, Egypt

\begin{abstract}
Aim: To evaluate the impact of adding L-carnitine (LC) to usual endometrial preparation on endometrial receptivity in women with at least one prior implantation failure during intra-cytoplasmic sperm injection (ICSI)/frozen embryo transfer (FET) cycles.

Methods: This prospective, double-blinded, placebo-controlled, randomized, parallel-group, concealed allocation, superiority trial was conducted at a private specialized IVF center at Benha, El-Qalubia, Egypt, between November 2015 and May 2017. The study included 124 infertile couples with at least one prior implantation failure (PIF) in ICSI/FET cycles; they were allocated to receive usual endometrial preparation plus $3 \mathrm{gm}$ LC/daily until transfer (62) or received placebo (62) plus usual estradiol valerate. Outcomes were endometrial thickness, implantation rate, chemical pregnancy rate, clinical pregnancy rate, ongoing implantation rate, ongoing pregnancy rate, live birth rate and live borne babies rate. Results: Infertile women with at least one prior implantation failure in ICSI/FET cycles co-treated with L-Carnitine showed significantly thicker endometrium $(\mathrm{mm}) 9.8 \pm 1.2$ in LC vs $8.4 \pm 0.7$ in non LC with $\Delta(95 \% \mathrm{CI})=1.4(1.74,1.05)$ and higher chemical pregnancy rate $46(74.2 \%)$ in LC vs $22(35.4 \%)$ in non LC with $\triangle \mathrm{PP}(95 \% \mathrm{CI})=38.8(71.46 ; 52.96)$ and $\mathrm{RR}(95 \% \mathrm{CI})=2.09(1.44,30.1)$ and $\mathrm{NNT}(95 \% \mathrm{CI})=3(2,5)$. Also, higher clinical pregnancy rate was $(34(54.8 \%))$ in LC vs $14(22.6 \%)$ in non LC with $\Delta \mathrm{PP}(95 \% \mathrm{CI})=32.2 \%(15.13,46.77)$ and $\mathrm{RR}(95 \% \mathrm{CI})=2.4(1.45,40.5)$ and NNT $(95 \% \mathrm{CI})=4(3-7)$ as well as higher live birth rate and live bone rate of singletons fetus $(P<0.05)$.

Conclusion: Data presented in this trial supported the supplementation of LC to usual endometrial preparation in women with at least one prior implantation failure in ICSI/FET cycles as it improved endometrial receptivity indicated by improved implantation rate, clinical pregnancy rate and live birth rate.
\end{abstract}

Key Words: Estradiol valerate, frozen embryos transfer, intra-cytoplasmic sperm injection, L-carnitine supplementation, prior implantation failure, recurrent implantation failure

Received: 13 July 2018, Accepted: 27 July 2018

Corresponding Author: Ehab Barakat, Department of Obstetrics and Gynecology, Faculty of Medicine Benha University, Benha, Egypt, Tel.: 01114346252, E-mail: drehabmarzouk@yahoo.com

ISSN: 2090-7265, August 2018, Vol.8, No. 3

\section{INTRODUCTION}

Carnitines, including L-carnitine (LC) and Acetyl L-carnitine (ACL) are water-soluble quasi-vitamins, are highly needed in mitochondrial metabolism both in energy production as well as DNA protection from oxidative stress (OS) of reactive oxygen species (ROS). LC and ACL are important systemically in B-oxidation of long-chain free fatty acid (FFA), maintaining coenzyme A (COA)/Acetyl COA ratio in ATP production, excretion of Acetyl COA ester, sparing vitamin $\mathrm{E}$ and reduction of OS as well as they have important reproductive functions being antioxidant, anti-apoptotic and anti-inflammatory ${ }^{[1,2]}$.

The beneficial impact of carnitines in treating male subfertility is well-known ${ }^{[2-6]}$. In-vitro studies showed that adding carnitine to culture media improves oocyte quality, maturation and embryo development ${ }^{[7-19]}$. Animal studies showed that the combination of carnitine and other nutrient supplementation improves reproductive parameters ${ }^{[20-27]}$. Investigators of female subfertility found that carnitine supplementation in human female with polycystic ovarian syndrome (POCS) improves general and mental health parameters as well as it improves OS biomarkers and decreases lipid peroxidation ${ }^{[28]}$. In addition, it reduces body mass index and improves glycemic control ${ }^{[29]}$, improves ovulation rate, increases mean endometrial thickness and pregnancy rate in before and after clinical trial design ${ }^{[30]}$, increases significantly the ovulation rates, number of oocytes $\geq 17 \mathrm{~mm}$, mean serum E2 on day of hCG injection, mean endometrial thickness, pregnancy rate as well as decrease miscarriage rate in 170 women with clomiphene 
citrate-resistant (CCR) PCOS treated with $250 \mathrm{mg}$ CC (daily) plus $3 \mathrm{gm} /$ daily oral LC versus $250 \mathrm{mg} \mathrm{CC} /$ daily alone in double-blind placebo-controlled clinical trial ${ }^{[31]}$. Also, researches in treating animal female infertility found that $1 \mathrm{mg} /$ daily $/ \mathrm{kg}$ LC supplementation from day-1 until parturition in female Swiss albino mice significantly increased litter size, weight of reproductive organs and thickness of endometrium ${ }^{[32]}$.

Repeated implantation failure (RIF) is a major problem in assisted reproduction treatment (ART). Diminished endometrial receptivity could be the major contributor to this problem in frozen embryo transfer of good-quality embryos. We hypothesized that adding LC to usual endometrial preparation prior to frozen embryo transfer (FET) in women with RIF could improve uterine receptivity. The aim of this trial was to access the impact of LC supplementation to the usual endometrial preparation in frozen embryos transfer (FET) cycles on uterine receptivity.

\section{PATIENTS AND METHODS}

This prospective, randomized, concealed allocation, parallel groups, double-blinded, placebo-controlled, superiority trial was conducted in a private IVF specialized center, Benha, El-Qalubia, Egypt, from November 2015 to May 2017. We obtained an approval to our study protocol from Benha Faculty of Medicine ethical committee as well as all study participants signed an informed written consent after counseling regarding the trial interventions.

We included a total of 124 infertile couples treated by intra-cytoplasmic sperm injection (ICSI) and frozen embryos transfer (FET). All included couples were with prior implantation failure at least once in ICSI/ FET cycles. Patients were recruited sequentially and allocated to oral L-carnitine supplementation or placebo at random 1:1 ratio. The study used statistician utilized computer random number generator to provide us with a different size of blocked randomized treatment allocation schedule. The treatment allocation schedule was supported by pharmacist who supplied us by oral LC syrup and the physically identical placebo syrup bottles. Women were randomized to either LC or placebo at start of endometrial preparation cycle for FET, after randomization blinding of investigation and patients were maintained until the end of the study. Women were prepared for FET by estradiol valerate (EV) tablet/12 hr (white tablets of cyclo-prognova ${ }^{\circledR}$, Bayer Schering Pharma Ag - Germany) from the 4th day of menstrual cycle and followed up with transvaginal ultrasound (TVS) until the endometrial thickness (ET) is $\geq$ $8 \mathrm{~mm}$. All women in this study were with $\geq$ one failed FET, with available good quality frozen embryos whatever the used induction protocol. Women in LC group received, in addition to EV, a $3 \mathrm{gm}$ of LC syrup ( $5 \mathrm{ml}$ of LC syrup $\AA / 12$ hours orally, Arab Company for Pharmaceuticals and Medicinal Plants (MEPACO MEDIFOOD), Enshas El Raml-Skarkeya, Egypt. While, women in the placebo group received an identically physically solution in similar bottle prepared specially for this study by a trained pharmacist who supported the treatment allocation schedule until the recruitment of all priorly calculated infertile couples with $\geq 1$ PIF with available good quality frozen embryos and the results was evaluated by the trial statistician.

We defined chemical pregnancy as BHCG $\geq 5 \mathrm{Miu} / \mathrm{ml}$ after day 14 of FET, while clinical pregnancy as a detected at least one intrauterine gestational sac with positive fetal heart activity on TVS in follow up visits. We calculated implantation rate as the number of gestational sacs divided by the number of FET, while chemical/clinical pregnancy rate calculated as the number of women with positive BHCG positive fetal heart activity divided by the number of women whom had transferred procedures, respectively. We defined ongoing pregnancy as the presence of at least one fetal heart activity on transabdominal ultrasound beyond 20 weeks gestation, and we calculated ongoing pregnancy rate as the number of women with positive fetal heart at $\geq 20$ weeks divided by the number of transferred procedures. Miscarriage was defined as any failed pregnancy prior to 20 -week gestation and miscarriage rate calculated as number of pregnancy losses prior to 20 weeks divided by number of women with chemical pregnancy ; while live birth rate was calculated as the number of live births divided by of transfer procedures and live borne baby rate was calculated as number of live borne babies divided by number of transferred procedures. The study main outcomes measures included clinical pregnancy rate, live birth rate and live borne rate; while the subsidiary outcomes included the chemical pregnancy rate, ongoing pregnancy rate, implantation rate, ongoing implantation rate and miscarriage rate.

We calculated sample size with aids of online website clinealc. Com / stats / sample size, aspx. The chemical pregnancy rate of patients with prior implantation failure (PIF) at least once in our infertility center in ICSI/FET cycles in prior 6 months was 35\% (relatively low), while the chemical pregnancy rate in first trial ICSI / FET cycle was $80 \%$ (relatively high). Assuming that adding L-carnitine to EV during endometrial perpetration for FET will increase the relatively low pregnancy rate in women with PIF by at least $75 \%$ (i.e. increase from $35 \%$ to 61.2\%), 56 infertile couples with PIF $\geq$ once are required in each group at double-sided $5 \%$ significance (type 1 error $(\alpha)=0.5$ ) and a power of $80 \%$ (type II error $(B)=0.2$ ). To compensate for $10 \%$ losses to follow up, we decided to include 124 infertile couple with PIF $\geq$ once in this study. 
Statistical analysis was done according to intensity to treat ITT analysis policy and was performed with aids of SPSS 20 for Windows (IBM, Chicago, IL, USA). We presented continuous variables in terms of mean \pm standard deviations, range and categorical variables in terms of numbers (percents), as appropriate. Chi-Square test was used to compare categorical variables; while independent student's t-test was used to compare continuous variables, as our data were normally distributed. We used $p$-value and point estimate difference with $95 \%$ confidence interfere $(95 \% \mathrm{CI})$ to determine significance, and we considered $P<0.05$ to be statistically significant.

\section{RESULTS}

In the current study, 150 ICSI/FET candidate with at least one prior implantation failure (PIF) of frozen embryos transfer (FET) and available good-quality were assessed to be included in this trial, only 124 signed written informed consent and randomized to either receiving L-carnitine (LC) in addition to usual endometrial preparation with estradiol valerate $(\mathrm{EV})$ or placebo plus $\mathrm{EV}$ as 62 women in each group. All randomized patients have received the allocated treatment as randomized, and all 124 patients were included in the final analysis as presented in Figure 1

Fig. 1: CONSORT participants flow in LC group versus NON-LC during in ICSI/FET cycles in PIF prevention trial

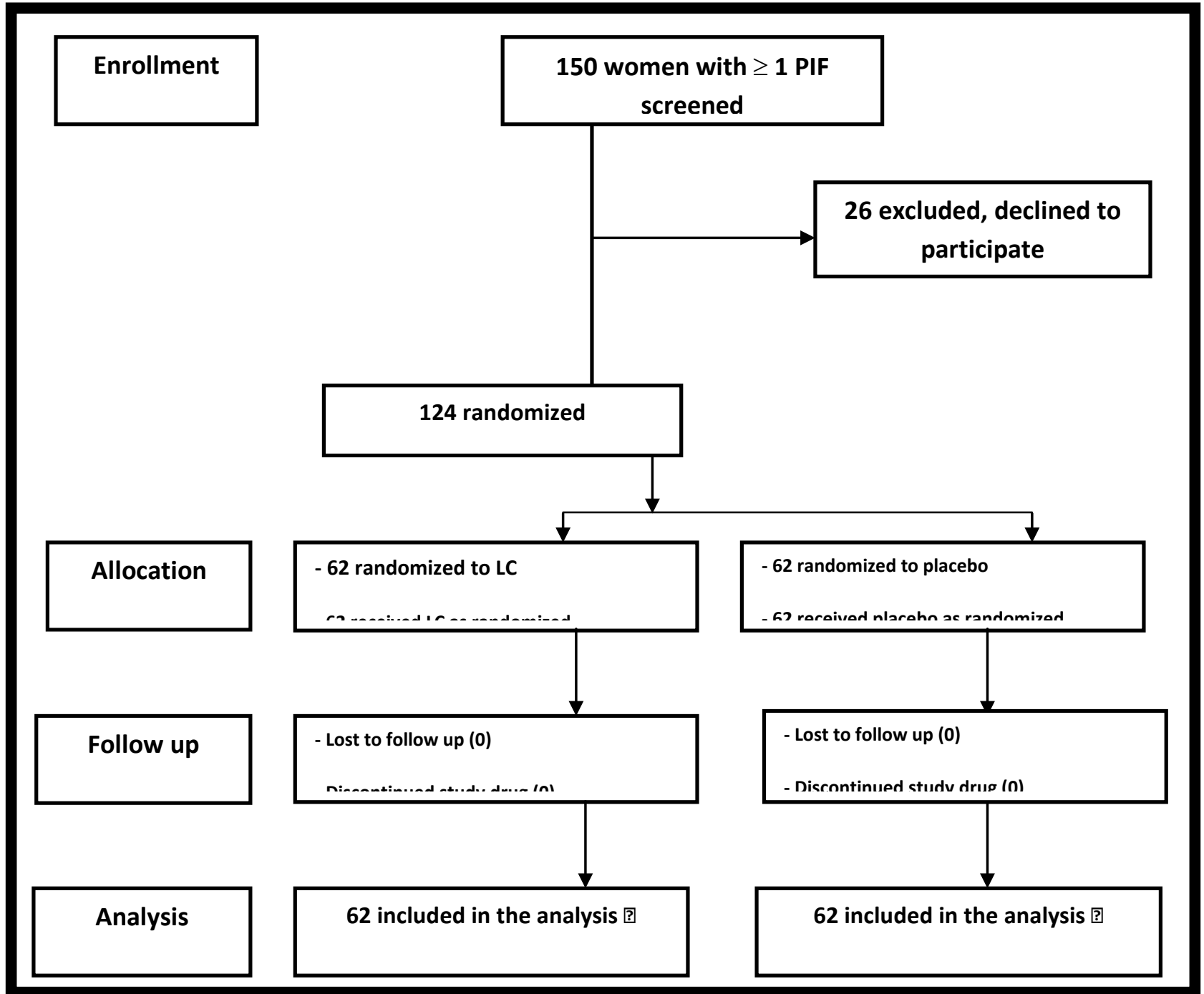

Abbreviations: CONSORT: Consolidated standards of reporting trials,

LC: L-carnitine, PIF: Prior implantation failure $\geq 1$, ICSI: Intracytoplasmic sperm injection, FET: Frozen embryos transfer 
Table 1 presents the trial participants baseline clinical and laboratory characteristics and shows that there was no statistically significant difference between participants in LC or non-LC groups

Table 1: Baseline characteristics of LC group and non-LC group during ICSI / FET cycle in PIF prevention trial

\begin{tabular}{lcccc}
\hline Variable & $\begin{array}{c}\text { LC group } \\
\text { (no }=62)\end{array}$ & $\begin{array}{c}\text { NON-LC group } \\
\text { (no }=62)\end{array}$ & $\Delta(95 \%$ CI) & $P$. value \\
\hline Age (y)* & $27.6 \pm 3.8(2.08-44.6)$ & $28.8 \pm 4.5(21-43)$ & $-1.2(0.28,-2.68)$ & 0.11 \\
BMI (kg/m2)* & $28.3 \pm 3.6(22.6-34.1)$ & $29.9 \pm 3.8(21.5-33.6)$ & $-1.1(0.21,-2.41)$ & 0.10 \\
Infertility duration (y)* & $6.8 \pm 2.8(3.6-20.8)$ & $7.6 \pm 4.8(2.8-21.6)$ & $-0.8(0.73,-2.33)$ & 0.30 \\
Infertility type: & & & & 0.59 \\
$\quad$ - Primary** & $38(59.6 \%)$ & $34(54.8 \%)$ & $4.8(-12.23,21,51)$ & 0.59 \\
$\quad$ - Secondary** & $24(40.4 \%)$ & $28(45.2 \%)$ & $-4.8(12.29,-21.51)$ & 1 \\
Infertility causes & & & & 0.65 \\
$\quad$ - Anovulation ** & $14(22.5 \%)$ & $14(22.6 \%)$ & $0(-14.64,14,64)$ & 0.65 \\
$\quad$ - Tubal factor ** & $13(20.9 \%)$ & $11(17.7 \%)$ & $3.2(10.79,17.08)$ & 0.51 \\
$\quad$ - Male factor** & $12(19.3 \%)$ & $14(22.6 \%)$ & $-3.3(-11.07,17,52)$ & 0.69 \\
$\quad$ - Endometriosis* & $4(6.4 \%)$ & $6(9.6 \%)$ & $-3.2(-7.14,13.79)$ & 0.60 \\
- Unexplained** & $19(30.6 \%)$ & $17(27.4 \%)$ & $-0.3(0.85,-1.45)$ & 0.48 \\
Basal FSH ( mIu/m2)* & $5.9 \pm 2.6(3.8-8.8)$ & $6.2 \pm 3.8(3.2-9.2)$ & $-0.5(0.91,-1.91)$ & 0.43 \\
Basal LH (mIu/ml)* & $4.7 \pm 2.8(3.5-8.9)$ & $5.2 \pm 4.9(3.1-8.5)$ & $-2(3.05,-7.05)$ & 0.58 \\
Basal E2 (pg/ml)* & $42.6 \pm 13.8(38.5-70.5)$ & $44.6 \pm 14.6(36.5-75.5)$ & $-0.2(0.53,-0.93)$ & 0.60 \\
Basal AMH (ng/ml)* & $2.6 \pm 1.9(1.6-9.8)$ & $2.8 \pm 2.2(1.2-8.9)$ & $0.6(-2.91,1.71)$ & 0.54 \\
Basal AFC (n)* & $15.2 \pm 6.2(6-22)$ & $14.6 \pm 6.8(7-24)$ & $-0.2(0.45,-0.85)$ & 0.59 \\
No. of PIF* & $1.9 \pm 1.8(1-5)$ & $2.1 \pm 1.9(1-6)$ & $0.4(-1.86,1.06)$ & \\
No. of FE* & $11.2 \pm 3.6(4-16)$ & $10.8 \pm 4.6(4-15)$ & & \\
\hline
\end{tabular}

Abbreviation: LC: L-carnitine, ICSI: Intra-cytoplasmic sperm injection, FET: Frozen embryos transfer, PIF: Prior implantation failure $\geq 1$, BMI: Body mass index, $\Delta(95 \% \mathrm{CI})$ : Mean or proportion percentage difference with $95 \%$ confidence interval, FE: Frozen embryos.

- Values were given as mean \pm standard deviation (range)* or number (percentage) **

$-P<0.05$ : Statistically significant.

Table 2 presents ICSI/FET cycles characteristics as well as outcomes differences between women received LC versus who didn't received LC in groups of women with at least one PIF aiming at improving endometrial receptivity (ER) and this table shows that receiving LC in addition to usual endometrial preparation with EV during ICSI/FET cycles was statistically significant in achieving thicker endometrial $(P<0.0001)$, reducing number of days of $\mathrm{EV}$ intake to reach endometrial thickness of $\geq 8 \mathrm{~mm}$ $(P<0.0001)$ and needless EV tablets to reach endometrial thickness of $\geq 8 \mathrm{~mm}(P<0.0001)$. Also, Table 2 shows that despite comparable number of apparently good frozen embryos transfer per women, the proportion of women with positive BHCG was significant statistically in favour of LC over non LC administration $46(74.2 \%)$ in LC versus $22(35.4 \%)$ in non $\mathrm{LC}$, proportion percentage difference $(\Delta \mathrm{PP})=38.8 \%$ with $95 \% \mathrm{CI}$ of 25.46 to 52.96 and relative risk (RR) of being +ve BHCG and use LC to be the +ve BHCG and non $\mathrm{LC}=2.09$ at $95 \% \mathrm{CL}$ of 1.44 to 3.01 and number need to treat (NNT) with LC to add more number of women with the +ve BHCG of 3 women with $\geq$ one PIF at $95 \%$ CI of 2 to 5 .
Furthermore, Table 2 shows that the number of women with at least one positive fetal heart pulsation (clinical pregnancy) was statistically significantly higher in group supplemented with LC $(34$ (54.8\%) in LC versus $14(22.6 \%)$ in non $\mathrm{LC}$ with $\Delta \mathrm{PP}=32.2 \%$ at $95 \% \mathrm{CI}$ of $15.13 \%$ to $46.77 \%$ and $\mathrm{RR}=2.4$ at $95 \%$ CI of 1.45 to 4.65 and NNT $=4(3-7)$. Additionally, Table 2 shows that implantation rate was significantly more in women receiving LC supplementation (48/139 (34.5\%) in LC group versus $19 / 140(13.5 \%)$ in non LC group with $\Delta \mathrm{PP}=21.21 \%$ at $95 \% \mathrm{CI}$ of 11.28 to 30.64 and $\mathrm{RR}=2.54$ at $95 \%$ of 1.57 to 4.09 and NNT $=5$ at $95 \%$ of 4 to 9 . Moreover, Table 2 presents that differences in ongoing implantation rate, ongoing pregnancy rate as well as live birth rate and live borne baby rate for singleton fetus were statistically significant in favor of LC supplementation over no LC supplementation as $\mathrm{p}$. values, respectively were $0.0008,0.0007,0.0009,0.0008$.

No apparent sequels were recorded in both groups could be attributable to L-carnitine supplementation as well as no congenital anomalies were recorded in delivered babies. 
Table 2: ICSI / FET cycles characteristics and outcomes differences between LC group and non-LC group in PIF prevention trial

\begin{tabular}{|c|c|c|c|c|}
\hline Variable & $\begin{array}{l}\text { LC group } \\
(\text { no }=62)\end{array}$ & $\begin{array}{l}\text { NON-LC group } \\
\quad(\text { no }=62)\end{array}$ & $\Delta(95 \% \mathrm{CI})$ & P. value \\
\hline $\begin{array}{l}\text { 1-Endometrial } \\
\text { thickness }(\mathrm{mm})^{*}\end{array}$ & $9.8 \pm 1.2(8-11)$ & $8.4 \pm 0.7(8-11)$ & $1.4(1.74 ; 1.05)$ & $<0.0001$ \\
\hline $\begin{array}{l}\text { 2-No. of days to } \\
\text { reach } 8 \mathrm{~mm} \mathrm{ET}^{*}\end{array}$ & $1.2 \pm 1.2(6-11)$ & $9.2 \pm 0.8(7-12)$ & $-2(-1.63,-2.36)$ & $<0.0001$ \\
\hline $\begin{array}{l}\text { 3-No. of tablets to } \\
\text { reach } 8 \mathrm{~mm} \mathrm{ET}^{*}\end{array}$ & $28.4 \pm 4.8(24-44)$ & $36.8 \pm 2.4(28-48)$ & $-8.4(-7.05,-9.74)$ & $<0.0001$ \\
\hline \multicolumn{5}{|l|}{$\begin{array}{l}\text { 4-No. of transferred } \\
\text { embryos/FET** }\end{array}$} \\
\hline 1 & $5(8 \%)$ & $8(12.9 \%)$ & $-4.9(6.40,-16.38)$ & 0.37 \\
\hline 2 & $37(59.6 \%)$ & $38(61.3 \%)$ & $-1.7(15.11,-18.37)$ & 0.84 \\
\hline 3 & $20(32.4 \%)$ & $16(25.8 \%)$ & $6.6(-9.28,22.05)$ & 0.42 \\
\hline $\begin{array}{l}\text { 5-Chemical } \\
\text { pregnancy }(n)(1) \%\end{array}$ & $46(74.2 \%)$ & $22(35.4 \%)$ & $38.8(21.46,52.96)$ & $<0.0001$ \\
\hline $\begin{array}{l}\text { 6-Clinical pregnancy } \\
(n)(2) \%\end{array}$ & $34(54.8 \%)$ & $14(22.6 \%)$ & $32.2(15.13,46.77)$ & $<0.0002$ \\
\hline \multicolumn{5}{|l|}{ 7-No. of Sacs** } \\
\hline 1 & $22(35.4 \%)$ & $10(16.1 \%)$ & $19.3(3.88,33.62)$ & 0.014 \\
\hline 2 & $10(16.1 \%)$ & $3(4.8)$ & $11.3(0.26,22.81)$ & 0.04 \\
\hline 3 & $2(3.2 \%)$ & $1(1.6 \%)$ & $1.6(-5.74,9.49)$ & 0.56 \\
\hline $\begin{array}{l}8 \text {-Implantation } \\
\text { rate }(n)(3) \%\end{array}$ & $48 / 139(34.5 \%)$ & $19 / 140(13.5 \%)$ & $21.2 \%(11.28,30,64)$ & $<0.0001^{*}$ \\
\hline $\begin{array}{l}\text { 9-Ongoing pregnancy } \\
\operatorname{rate}(n)(4) \%\end{array}$ & $30(48.3 \%)$ & $12(19.3 \%)$ & $29 \%(12.40,43.51)$ & 0.0007 \\
\hline $\begin{array}{l}\text { 10- Ongoing } \\
\text { implantation } \operatorname{rate}(n)(5) \%\end{array}$ & $38 / 139(27.3 \%)$ & $16 / 140(11.4 \%)$ & $15.9(6.67,24.91)$ & 0.0008 \\
\hline $\begin{array}{l}11-\text { Miscarriage } \\
\text { rate }(n)(6) \%\end{array}$ & $12 / 46(26.1 \%)$ & $8 / 22(36.3 \%)$ & $10.2(-11.63,33.39)$ & $0.39 *$ \\
\hline $\begin{array}{l}\text { 12- Live birth } \\
\text { rate }(n)(7) \%\end{array}$ & $30(46.8 \%)$ & $12(18.7 \%)$ & $28.1(11.63,42.59)$ & 0.0009 \\
\hline \multicolumn{5}{|l|}{$\begin{array}{l}\text { 13-Live borne baby } \\
\text { rate }(n)(8) \%\end{array}$} \\
\hline $\begin{array}{l}1 \\
2 \\
3\end{array}$ & $\begin{array}{c}23(37 \%) \\
6(9.6 \%) \\
1(1.6 \%)\end{array}$ & $\begin{array}{c}10(16.1 \%) \\
2(3.2 \%) \\
0(0 \%)\end{array}$ & $\begin{array}{c}20.9(5.34,35,23) \\
6.4(-2.92,16.52)\end{array}$ & $\begin{array}{c}0.008 \\
0.14\end{array}$ \\
\hline
\end{tabular}

Abbreviation: LC: L-carnitine, ICSI: Intra-cytoplasmic sperm injection,

FET: Frozen embryos transfer, PIF: Prior implantation failure $\geq 1$, BMI: Body mass index, EM: Endometrial thickness, $\Delta(95 \% \mathrm{CI})$ : Mean or proportion percentage difference with $95 \%$ confidence interval, FE: Frozen embryos.

- Values were given as mean \pm standard deviation (range)* or number (percentage) **

$-P<0.05$ : Statistically significant.

(1) no. of women with positive BHCG/ transferred procedures

(2) no. of women with positive fetal heart activity/transferred procedures

(3) no. of fetal sacs / transferred embryos.

(4) no. of women with $\geq$ one living fetus at $\geq 20$ weeks / transferred procedures

(5) no. of living fetuses at $\geq 20$ weeks / transferred embryos

(6) no. of pregnancy losses before 20 weeks/no. of +ve BHCG.

(7) no. of women with live birth / transferred procedures

(8) no. of babies born/transferred procedures 


\section{DISCUSSION}

This study demonstrated that supplementation with LC at a dose of $3 \mathrm{gm} /$ daily in two doses 12 hour apart starting at endometrial preparation with estradiol valerate in women at least one prior implantation failure (PIF) with available good quality frozen embryos successfully improves endometrial receptivity, as this supplementation increases average endometrial thickness, reduces number of days as well as number of estradiol valerate tablets to reach adequate endometrial thickness for FET, increases chemical pregnancy rate as well as clinical pregnancy rate, improves implantation rate, ongoing implantation rate, ongoing pregnancy rate and the live birth rate as well as live borne rate.

We could not find similar trial evaluating the impact of adding LC to usual endometrial preparation in ICSI/FET cycles after searching data bases including MEDLINE via PUBMED and OVID, SCOPUS, EMBASE, EBSCO. However, there was a doubleblind, randomized, placebo-controlled, superiority trial $^{[31]}$ evaluating the impact of LC supplementation to CCR-PCOs women at $3 \mathrm{gm} \mathrm{LC} /$ daily with $250 \mathrm{mg}$ $\mathrm{CC}$ and the investigators reported that group of women received LC were significantly higher in ovulation rate 5564.4\%) 85/) in LC group versus $1317.4 \%$ ) 85/) with $P<0.0001$, shorter duration till $\mathrm{HCG}$ injection $8.55 \pm 0.99$ in $\mathrm{LC}$ versus $13.65 \pm 0.98$ in non $\mathrm{LC}$ with $P<0.0001$, thicker endometrium in $(\mathrm{mm})$ $10.66 \pm 0.68$ in $\mathrm{LC}$ versus $6.08 \pm 0.59$ in non $\mathrm{LC}$ with $<0.0001$, highly chemical pregnancy rate $55(51.5 \%)$ in LC versus $5(5.8 \%)$ in non LC with $P<0.0001$ and significantly higher clinical pregnancy rate $42(49.4 \%)$ in LC versus $1(1.1 \%)$ in non LC with $P<0.0001$ and lower non-statistically significant miscarriage rate $2(2.4 \%)$ in LC versus $9(4.7 \%)$ in non LC with $P=0.67$. The results of LC supplementation to CCR-PCOS were in parallel to our results ; despite that, the study evaluated the total effect of LC supplementation to infertile CCR-PCOS on ovarian functions as well as endometrial receptivity. While, our study concentrates on evaluating the effect of LC on endometrial receptivity. The researchers of LC trial on CCR-PCOS women reported significant thicker endometrium as our study and also significantly high +ve BHCG, implantation rate, women with +ve fetal heart activity as well as lower non-statistically significant miscarriage rate and all this in our trial could be explained through effect of LC on endometrium ; while in trial of LC co-treatment in CCR-PCOS women could be explained partially through impact of LC on endometrium. Investigators in animal studies ${ }^{[32]}$ found that adding LC at 0.5 and $1 \mathrm{gm} / \mathrm{kg}$ from day 1 till parturition to female Swiss albino mice at 12-14 week of age significantly increased FSH, LH, and estradiol levels as well as increased the litter size, weight of reproductive organs and thickness of endometrium, this in parallel with our results that LC supplementation increase the thickness of endometrium.

The impact of LC in endometrium could be explained through its systemic effects, in general in energy production, and its reproductive effects $^{[1,2]}$; namely, antioxidant effects including the free radical scavenging, elimination of excess FFA from endoplasmic reticulum (ER), elevating to antioxidant enzymes activities as well as anti-apoptotic effects including the regulators for tumor suppressor protein, suppressor to the action of caspases 3,7,8 and anti-inflammatory effects as LC decrease the proinflammatory cytokines level like tumor necrosis factor $\alpha$ (TNF- $\alpha$ ), interleukin-6,2 (IL-6,2), interferon (IFN) and others. Thus, LC supplementation could counteract the reported dysregulated energy production, genes expression and genes transcription reported in women with recurrent implantation failures (RIF) ${ }^{[33-37]}$.

The strength points of the present study include being prospective, randomized, double-blinded, placebo-controlled as well as its design enable us to answer the study question which was the impact of LC supplementation on endometrial receptivity as we chose women with $\geq 1 \mathrm{PIF}$ in ICSI/FET cycles who had adequate high quality frozen embryos, so PIF could be attributed to poor endometrial receptivity as well as this trial positively affect endometrium receptivity with higher pregnancy rate, higher live birth rate could be exclusively due to the effect of co-treatment of endometrial preparation for FET by LC supplementation. Also, strength points of this study included an adequate power to detect clinically beneficial outcomes (pregnancy rate, live birth rate) not only intermediate surrogate outcomes (endometrial thickness, the +ve BHCG).

While, the limitations of this trial include that it could not be generalized to all ICSI patients as well as it could not be generalized to women without prior implantation failures in ICSI/FET cycles. So, we recommended further research on supplementation of LC to women who will undergo first FET trial as well as during induction with fresh embryos transfer and evaluating the impact of LC supplementation on endometrial transcription, subendometrial vascularization as well as uterine Doppler blood flow incidences. 


\section{CONCLUSION}

The current trial demonstrated the significant beneficial effect of adding $3 \mathrm{gm} /$ daily L-carnitine to usual endometrial preparation with estroidal valerate on increasing endometrial receptivity in women with at least one prior implantation failure in ICSI/FET cycles, as adding L-carnitine significantly increases endometrial thickness, pregnancy rates, implantation rate, and live birth rate.

\section{ACKNOWLEDGMENT}

The authors are thankful to their patients, colleges, fellows, data collectors to at the IVF center who helped them in conducting this trial.

\section{CONFLICT OF INTEREST}

There are no conflicts of interest

\section{REFERENCES}

1. Ashok Agarwal, Pallav Sengupta, and Damayanthi Durairajanayagam. Role of L-carnitine in female infertility. Reproductive Biology and Endocrinology (2018) 16: 5.

2. Mongioi L, Calogero AE, Vicari E, Condorelli RA, Russo GI, Privitera S, et al. The role of carnitine in male infertility. Andrology. 2016;4:800-807.

3. Lenzi A, Sgrò P, Salacone P, Paoli D, Gilio B, Lombardo $\mathrm{F}$, et al. A placebo-controlled doubleblind randomized trial of the use of combined 1-carnitine and 1-acetylcarnitine treatment in men with asthenozoospermia. Fertil Steril. 2004;81:1578-1584.

4. Balercia G, Regoli F, Armeni T, Koverech A, Mantero F, Boscaro M. Placebo-controlled double-blind randomized trial on the use of L-carnitine, L-acetylcarnitine, or combined L-carnitine and L-acetylcarnitine in men with idiopathic asthenozoospermia. Fertil Steril. 2005; 84 : 662-671.

5. Cavallini G, Ferraretti AP, Gianaroli L, Biagiotti G, Vitali G. Cinnoxicam and L-carnitine/acetyl-Lcarnitine treatment for idiopathic and varicoceleassociated oligoasthenospermia. J Androl. 2004;25:761 - 770. discussion 771-2.

6. Moslemi Mehni N, Ketabchi AA, Hosseini E. CombinationeffectofPentoxifyllineandL-carnitine on idiopathic oligo-asthenoteratozoospermia. Iran J Reprod Med. 2014; 12 : 817-824.
7. Abdelrazik H, Agarwal A. L-carnitine and assisted reproduction. Arch Med Sci. 2009; 1A : S43 -7.

8. Wu GQ, Jia BY, Li JJ, Fu XW, Zhou GB, Hou YP, Zhu SE. L-carnitine enhances oocyte maturation and development of parthenogenetic embryos in pigs. Theriogenology. 2011; $76: 785-93$.

9. Reader KL, Cox NR, Stanton JA, Juengel JL. Effects of acetyl-L-carnitine on lamb oocyte blastocyst rate, ultrastructure, and mitochondrial DNA copy number. Theriogenology. 2015; 83 : 1484-92.

10. You J, Lee J, Hyun SH, Lee E. L-carnitine treatment during oocyte maturation improves in vitro development of cloned pig embryos by influencing intracellular glutathione synthesis and embryonic gene expression. Theriogenology. $2012 ; 78: 235-43$.

11. Mansour G, Abdelrazik H, Sharma RK, Radwan E, Falcone T, Agarwal A. L-carnitine supplementation reduces oocyte cytoskeleton damage and embryo apoptosis induced by incubation in peritoneal fluid from patients with endometriosis. Fertil Steril. 2009; $91: 2079-86$.

12. Somfai $\mathrm{T}$, Kaneda $\mathrm{M}$, Akagi $\mathrm{S}$, Watanabe $\mathrm{S}$, Haraguchi S, Mizutani E, Dang-Nguyen TQ, Geshi M, Kikuchi K, Nagai T. Enhancement of lipid metabolism with L-carnitine during in vitro maturation improves nuclear maturation and cleavage ability of follicular porcine oocytes. Reprod Fertil Dev. 2011; 23:912-20.

13. Moawad AR, Xu B, Tan SL, Taketo T. L-carnitine supplementation during vitrification of mouse germinal vesicle stage-oocytes and their subsequent in vitro maturation improves meiotic spindle configuration and mitochondrial distribution in metaphase II oocytes. Hum Reprod. 2014; 29 : 2256-68.

14. Mishra A, Reddy IJ, Gupta PS, Mondal S. L-carnitine mediated reduction in oxidative stress and alteration in transcript level of antioxidant enzymes in sheep embryos produced in vitro. Reprod Domest Anim. 2016; 51 : 311-21.

15. Zare Z, Masteri Farahani R, Salehi M, Piryaei A, Ghaffari Novin M, Fadaei Fathabadi F, Mohammadi M, Dehghani-Mohammadabadi M. Effect of L-carnitine supplementation on maturation and early embryo development of immature mouse oocytes selected by brilliant cresyle blue staining. J Assist Reprod Genet. $2015 ; 32: 635-43$ 
16. Phongmitr T, Liang Y, Srirattana K, Panyawai $\mathrm{K}$, Sripunya N, Treetampinich C, Parnpai R. Effects of L-carnitine supplemented in maturation medium on the maturation rate of swamp buffalo oocytes. Buffalo Bulletin. 2013; 32 : 613-6.

17. Takahashi T, Inaba Y, Somfai T, Kaneda M, Geshi M, Nagai T, Manabe N. Supplementation of culture medium with L-carnitine improves development and cryotolerance of bovine embryos produced in vitro. Reprod Fertil Dev. 2013; 25 : 589-99.

18. Manzano PCVJ, Ocampo MB, Ocampo LC, Maylem ERS, Lazaro JV. Improved bovine blastocyst developmental potential by L-carnitine supplementation. Int J Sci Res Knowledge. 2015; 3 : 021-9.

19. Khanmohammadi N, Movahedin M, Safari M, Sameni HR, Yousefi B, Jafari B, Zarbakhsh S. Effect of L-carnitine on in vitro developmental rate, the zona pellucida and hatching of blastocysts and their cell numbers in mouse embryos. Int $\mathrm{J}$ Reprod Biomed (Yazd). 2016; 14 : 649-56.

20. Samland CJ, Musser RE, Peters JK, Sawyer JT, Owen KQ, Davis DL. Ovulation and fertilization rate of gilts provided additional L-carnitine and chromium nicotinate. In: Kansas Agricultural Experiment Station Research Reports, editor, Swine Day. Manhattan: Agri Exp Station Cooper Ext Service. 1998; 25-7.

21. Pirestani A, Aghakhani M, Tabatabaei SN, Ghalamkari G, Baharlo F. Effects of dietary L-carnitine and choline chloride compound on reproduction indices and udder immune system in Holstein dairy cattle. In: Proceedings of international conference on life Science and Technology. 2011; 59-61.

22. Adabi SG, Moghaddam G, Taghizadeh A, Nematollahi A, Farahvash T. Effect of L-carnitine and vegetable fat on broiler breeder fertility, hatchability, egg yolk and serum cholesterol and triglyceride. Int J Poult Sci. 2006; 5 : 970-4.

23. Virmani MA, Zerelli S, Vitullo P, Cossetti C. Effect Of nutrients on ovulation and oocytes quality in mice. In: Proceedings of 11 th congress of the European Society of Gynecology. Roma: Edizioni Internazionali; 2015; 212-4.

24. Giorgi VS, Da Broi MG, Paz CC, Ferriani RA, Navarro PA. N-acetyl-cysteine and l-carnitine prevent meiotic oocyte damage induced by follicular fluid from infertile women with mild endometriosis. Reprod Sci. 2016; 23 : 342-51.
25. Abdel-Khalek AE, El-Ratel IT, Wafa WM, ElNagar HA, Younan GE, Fouda SF. Effect of pre-conception coenzyme Q10 and L-carnitine treatments on ovulatory response, genital characteristics and in vitro embryo characteristics in rabbits. Asian J Anim Vet Adv. 2015;11 : 53-9.

26. MSH H, Youssef SF, El-bahy MA. Effects of L-carnitine and ascorbic acid supplementation on productive, reproductive, physiological and immunological performance of golden montazah laying hens. Egypt Poult Sci. 2011; 31: 557-78.

27. Cavallini G, Magli MC, Crippa A, Ferraretti AP, Gianaroli L. Reduction in sperm aneuploidy levels in severe oligoasthenoteratospermic patients after medical therapy: a preliminary report. Asian J Androl. 2012; 14 : 591-8.

28. Jamilian H, Jamilian M, Samimi M, Afshar Ebrahimi F, Rahimi M, Bahmani F, Aghababayan S, Kouhi M, Shahabbaspour S, Asemi Z. Oral carnitine supplementation influences mental health parameters and biomarkers of oxidative stress in women with polycystic ovary syndrome: a randomized, double-blind, placebo-controlled trial. Gynecol Endocrinol. 2017; 33 : 442-7.

29. Samimi M, Jamilian M, Ebrahimi FA, Rahimi M, Tajbakhsh B, Asemi Z. Oral carnitine supplementation reduces body weight and insulin resistance in women with polycystic ovary syndrome: a randomized, double-blind, placebo-controlled trial. Clin Endocrinol. 2016; $84: 851-7$.

30. Latifian S, Hamdi K, Totakneh R. Effect of addition of 1-carnitine in polycystic ovary syndrome (PCOS) patients with clomiphene citrate and gonadotropin resistant. Int J Curr Res Acad Rev. 2015; 3: 469-76.

31. Ismail AM, Hamed AH, Saso S, Thabet HH. Adding L-carnitine to clomiphene resistant PCOS women improves the quality of ovulation and the pregnancy rate. A randomized clinical trial. Eur J Obstet Gynecol Reprod Biol. 2014; 180:148-52.

32. MBMR F, Flayyih NK. Effect of L-carnitine administration to pregnant mice on some reproductive hormones and organs. Iraqi $\mathrm{J}$ Vet Med. 2012;36 : 68-74.

33. Koler M, Achache H, Tsafrir A, Smith Y, Revel A, Reich R. Disrupted gene pattern in patients with repeated in vitro fertilization (IVF) failure. Hum Reprod. 2009; 24(10): 2541-2548. 
34. Altmäe S, Martínez-Conejero JA, Salumets A, Simón C, Horcajadas JA, Stavreus-Evers A. Endometrial gene expression analysis at the time of embryo implantation in women with unexplained infertility. Mol Hum Reprod. 2010;16(3):178-187.

35. Koot YE, van Hooff SR, Boomsma CM, van Leenen D, Groot Koerkamp MJ, Goddijn M, Eijkemans MJ, Fauser BC, Holstege FC, Macklon NS. An endometrial gene expression signature accurately predicts recurrent implantation failure after IVF. Sci Rep. 2016; $6: 19411$.

36. Lédée N, Munaut $C$, Aubert J, Sérazin V, Rahmati M, Chaouat G, Sandra O, Foidart JM. Specific and extensive endometrial deregulation is present before conception in IVF/ICSI repeated implantation failures (IF) or recurrent miscarriages. J Pathol. 2011;225(4):554-564.

37. Fenkci SM, Fenkci V, Oztekin O, Rota S, Karagenc N. Serum total L-carnitine levels in non-obese women with polycystic ovary syndrome. Hum Reprod. 2008; 23 : 1602-6.

38. Altmäe S, Tamm-Rosenstein K, Esteban FJ, Simm J, Kolberg L, Peterson H, Metsis M, Haldre K, Horcajadas JA, Salumets A, Stavreus-Evers A. Endometrial transcriptome analysis indicates superiority of natural over artificial cycles in recurrent implantation failure patients undergoing frozen embryo transfer. Reprod Biomed Online. 2016 : 32(6) : 597-613. 